\title{
Energy from geo-structures: a topic of growing interest
}

1 Marco Barla PhD

Research Associate and Adjunct Professor, Department of Structural, Building and Geotechnical Engineering, Politecnico di Torino, Torino, Italy
2 Andrea Perino PhD

Research Assistant, Department of Structural, Building and Geotechnical Engineering, Politecnico di Torino, Torino, Italy
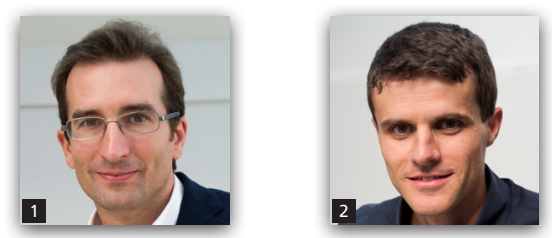

Underground geotechnical structures (piles, diaphragm walls, tunnel linings, anchors etc.) can be instrumented to become energy geo-structures. This short paper focuses on the use of energy tunnels, which are shown to have a number of advantages. An example of a possible application to the Turin Metro Line 1 south extension is discussed. Preliminary results of numerical analyses, performed to study the hydro-thermal interaction and the influence of the energy tunnel on the surroundings, show that the energy stored in the ground can be exploited without generating relevant effects on the aquifer. This highlights the importance of additional research to improve the understanding of the geothermal process and exploit the potential of energy tunnels allowing for great economic and environmental benefit.

\section{From energy piles to energy tunnels}

The demand of energy in the world is continuously growing and is still currently satisfied mainly by oil, natural gas and coal. At the same time, high levels of air pollution and lack of green spaces affect the major cities leading to an increasing use of the underground for transportation and utilities. The need to develop local and low-environmental-impact energy resources becomes more and more necessary. In this context, geothermal energy may play an important role, and its growth potential should be investigated. In general, geothermal systems can be classified as deep or shallow. The deep systems extract terrestrial heat from the earth at depths higher than $400 \mathrm{~m}$. These systems allow producing of electricity and involving temperatures higher than $100^{\circ} \mathrm{C}$. Shallow geothermal systems are instead used for domestic heating and cooling. This is currently done with closed-loop systems or by retrieving water from wells and re-injecting it in the aquifer after heat exchange (open-loop systems).

Underground civil infrastructures may act as a heat exchanger to exploit geothermal energy, with great economic and environmental benefit. Planning of underground systems (shallow or deep tunnels, foundations etc.) over the years very rarely took into account the opportunity to enhance them as geothermal resources. As described by Brandl (2006) and Adam and Markiewicz (2009), all geotechnical structures, such as piles, diaphragm walls, basement slabs or walls, tunnel linings and anchors in tunnels or in retaining structures, can be instrumented to become energy geo-structures. Examples exist where heat exchangers have been installed in piles and retaining walls
(Adam and Markiewicz, 2009; Brandl, 2006; Laloui and Di Donna, 2011; Nicholson et al., 2013). In more recent years, some authors have proposed to apply them to tunnels (Brandl, 2006; Franzius and Pralle, 2011; Lee et al., 2012; Markiewicz and Adam, 2003; Nicholson et al., 2013; Schneider and Moormann, 2010; Wilhelm and Rybach, 2003; Zhang et al., 2013). With respect to building foundations, tunnels involve a larger volume of ground and surface for heat exchange. Moreover, when mechanised tunnelling is used, tunnel linings are precast in a factory and then placed on site by the tunnel boring machine (TBM). The segmental lining can therefore be prepared and optimised for heat exchange. The system may also allow cooling the tunnel from the heat produced internally.

Despite the first promising examples, a number of aspects still need to be investigated before 'energy tunnels' can be considered a costeffective alternative to traditional heating systems.

The first key aspect is related to the design of the technological system that allows for a large-scale, real application. New materials and techniques that can allow optimising the process have to be taken into account.

The second aspect is the ability to quantify the heat that can be exploited from the ground, as a function of the exchange surface available. This calls for the need to study the hydrothermal interaction between the ground and the structural elements by advanced numerical modelling and site experiments (in situ thermal response tests). 


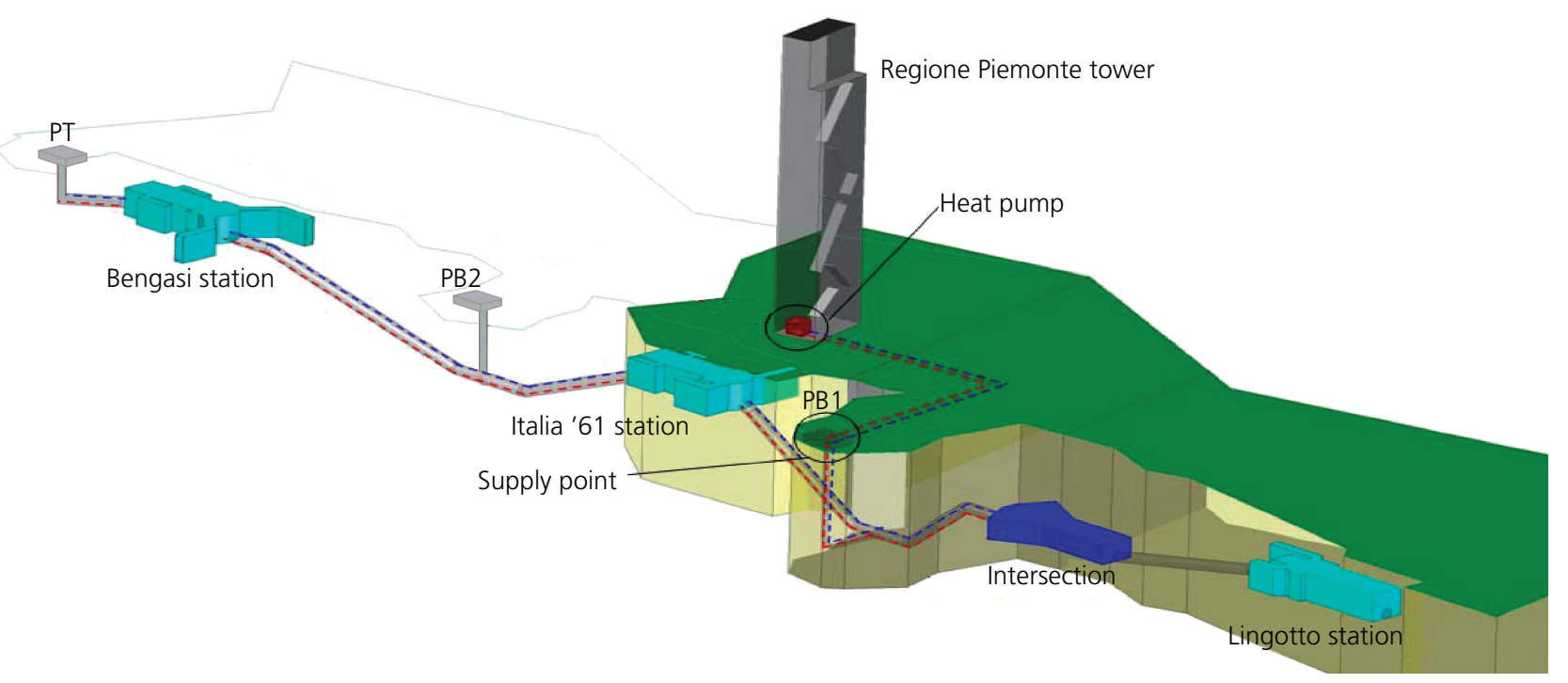

Figure 1. View of the Turin Metro Line 1 South Extension tunnel alignment and the proposed geothermal plant connected to the Regione Piemonte tower

The third aspect is the sustainability of the system in the long term. This includes the behaviour of the tunnel lining as well as the influence on the surroundings in terms of increase in the temperature in the aquifer and subsidence or deformations in the pre-existing buildings.

\section{An opportunity for the Turin Metro South Extension tunnel}

Tunnel construction works in Turin (Italy) provide a good opportunity to test the technology. Here, the authors are investigating the possible use of the tunnels of the Turin Metro Line 1 South Extension, currently under construction, to exploit heat for the Regione Piemonte new headquarters tower, which is also under construction (Figure 1). The system would allow to cover at least half of the building heating/cooling demand year round.

The section of interest is located in the southeastern suburbs of the city and includes two stations ('Italia '61' and 'Bengasi'), two ventilation shafts (PB1 and PB2), the end shaft (PBT, located $200 \mathrm{~m}$ beyond the last station (Bengasi)), and an intersection tunnel to allow for a future distribution line to the Lingotto railway station. The 1.9-km-long section is all underground at an average depth of $15 \mathrm{~m}$, below the groundwater table and runs very close to the new 220-m tower under construction.

The tunnel is excavated by an approximately 8 -m-diameter shielded earth pressure balance TBM. The precast concrete segmental lining is constituted by rings of seven elements. Cement foam is injected to guarantee full contact with the ground, and the segments are appropriately sealed in order to avoid groundwater ingress.

The proposed technical solution uses the lining as the geothermal heat exchanger (Barla and Perino, 2014). A working fluid (e.g. glycol propylene mixed with water that can work down to a temperature of $-20^{\circ} \mathrm{C}$ ) is conveyed through a net of pipes submerged in the concrete of the segments (Figure 2) and to a geothermal heat pump to cover the heating/cooling demand of the tower. The pipes are

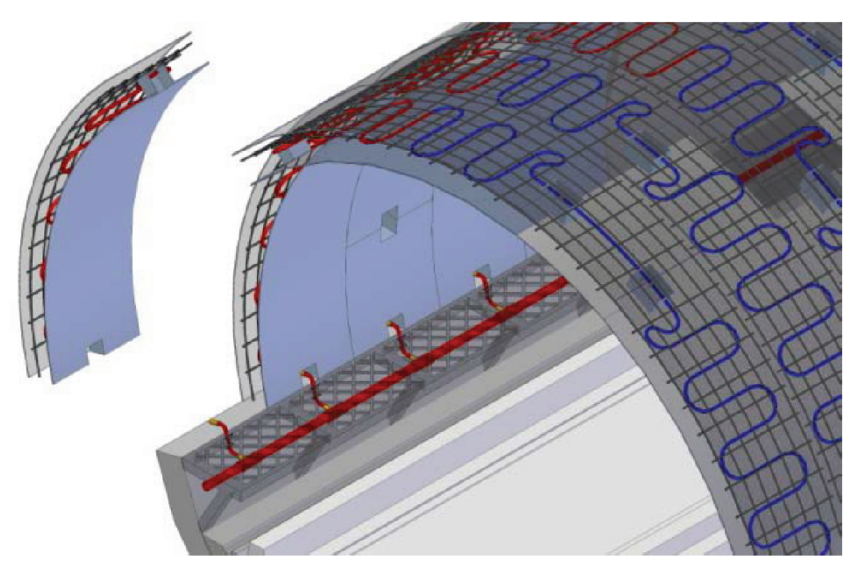

Figure 2. Sketch of the proposed installation scheme of the geothermal pipes submerged into the concrete segmental lining of the Turin Metro Line 1 South Extension tunnel 
fabricated in reticulated polyethylene (Pe-Xa) and are able to withstand high pressures and temperatures, resist to corrosion and guarantee high durability. Connections between segments are planned to be completed after the segmental lining is installed. In order to allow for easy inspection during the tunnel lifetime with the metro system in service, only the four segments installed in the upper section of the tunnel are instrumented with geothermal pipes. Both the inflow and the outflow pipes are located in the sidewalls of the tunnel, below the security pedestrian footpath.

To study the influence on the environment once the geothermal system is put in service, a number of coupled thermal fluid flow

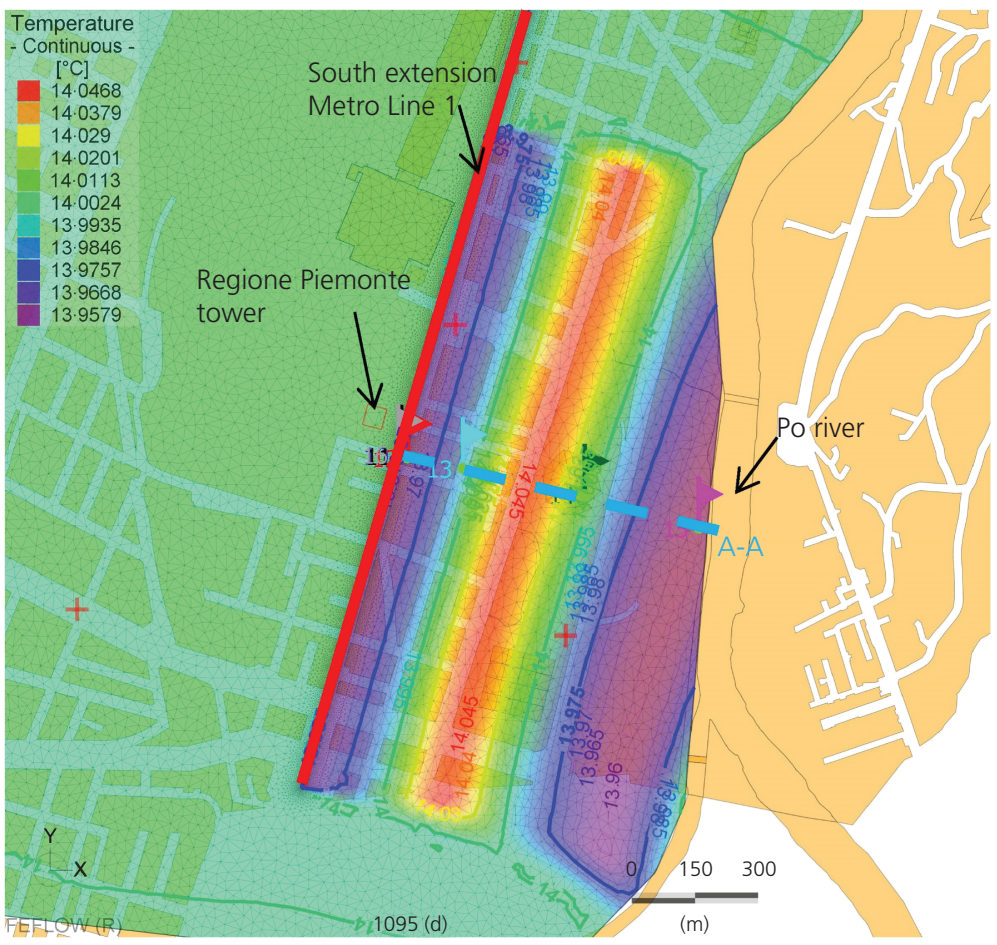

(a)

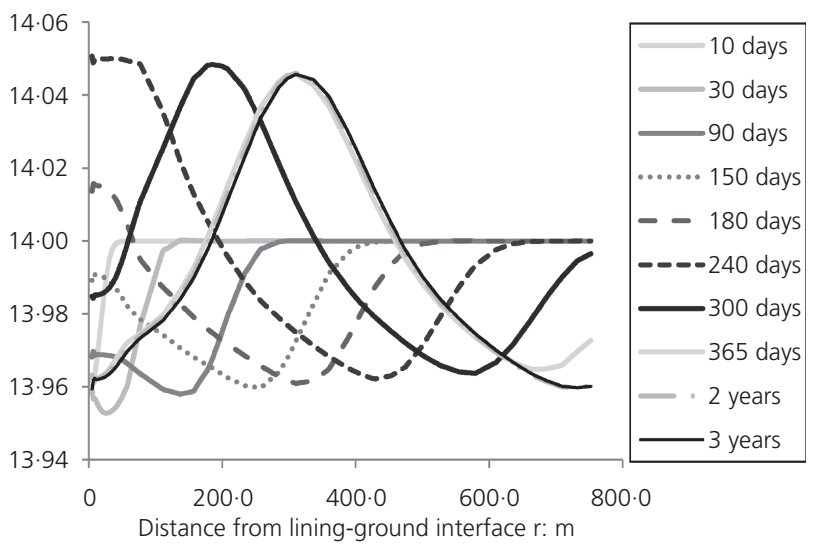

(b)

Figure 3. (a) Thermal plume at the end of the third year of simulation and (b) temperature versus distance from the liningground distance (section A-A) (applied heat flux of $10 \mathrm{~W} / \mathrm{m}^{2}$ ) 
numerical analyses were executed with the finite element method (FEM) software FEFLOW (Diersch, 2009) in the framework of a research project at the Politecnico di Torino.

The Turin subsoil is constituted by glaciofluvial formations and hosts an unconfined aquifer (Barla and Barla, 2012). At the site investigated, the water table surface is about $12 \mathrm{~m}$ below the ground level. The thickness of the aquifer is estimated to be $22-23 \mathrm{~m}$ (Civita and Pizzo, 2001).

The ground around the tunnel was assumed thermally isotropic and homogeneous. The hydraulic, hydrodispersive and thermal parameters of the aquifer used in the numerical analyses were obtained from standard pumping tests and large-scale tests. In these large-scale tests, the temperature and the hydraulic level were monitored for three months (Barla et al., 2013). The water in the aquifer has an average temperature of $14^{\circ} \mathrm{C}$ and flows towards the Po river (versus SE).

Numerical analyses considered three different working hypotheses for the geothermal system.

1. constant continuous heat extraction from the ground (H1)

2. variable heat extraction, as a function of the seasonal change in heating demand (H2)

3. extraction and injection of heat, for winter heating and summer cooling demands (H3).

The simulations considered a time scale of three years.

As an example, the thermal plume at the end of the three-year simulation for $\mathrm{H} 3$ and the temperature versus the distance from the tunnel contour are plotted in Figure 3. The temperature decrease from the undisturbed value of $14^{\circ} \mathrm{C}$ occurs during the winter because of heat extraction for heating demand, while the reverse behaviour is shown in summer. Additional analyses show that the temperature around the tunnel is strongly influenced by the water flow in the aquifer, which allows for a very fast recovery of the undisturbed temperature with less than $0 \cdot 2^{\circ} \mathrm{C}$ variation in the ground year round. The heating-cooling (H3) appears to be the best working hypothesis and allows an efficient recovery of the original temperature with no accumulation versus time.

\section{Perspectives}

These preliminary results show that the activation of the tunnel lining of the Turin Metro Line 1 would allow exploiting the energy stored in the ground with great economic and environmental benefit and without generating relevant effects on the aquifer.

These findings are in line with research results previously mentioned and call for the need to improve the understanding of the geothermal process in order to exploit the potential use of underground infrastructures as effective and innovative heat exchangers for the future. In this perspective, future research directions will consider the planning of a large-scale test to be performed during tunnel construction. A limited number of segmental lining elements could be installed and equipped with the net of pipes necessary to exploit heat and thermocouples displaced into the ground. Such a setting may allow to simulating summer and winter working conditions. Direct site validation of the parameters adopted for the numerical analyses is necessary for an improved and reliable quantification of the benefits achievable by extending the geothermal system to the whole tunnel length.

\section{REFERENCES}

Adam D and Markiewicz R (2009) Energy from earth-coupled structures, foundations, tunnels and sewers. Géotechnique 59(3): 229-236.

Barla M and Barla G (2012) Torino subsoil characterisation by combining site investigations and numerical modelling. Geomechanik und Tunnelbau 5(3): 214-231.

Barla M and Perino A (2014) Geothermal heat from the Turin metro south extension tunnels. Proceedings of the World Tunnel Congress 2014 - Tunnels for a Better Life. CRC Press/ Balkema, Foz do Iguaçu, Brazil.

Barla G, Antolini F, Barla M et al. (2013) Analisi e Verifica delle Condizioni di Esercizio in Sicurezza del Palazzo Uffici Provinciali di Corso Inghilterra 7 tenuto conto del Centro Direzionale di Intesa Sanpaolo. Technical report on pumping tests (n. rep. 52, 15.12.2011). Politecnico di Torino, Torino, Italy.

Brandl H (2006) Energy foundations and other thermo-active ground structures. Géotechnique 56(2): 81-122.

Diersch HJG (2009) DHI Wasy Software - Feflow 6.1 - Finite Element Subsurface Flow \& Transport Simulation System: Reference Manual. DHI Wasy GmbH, Berlin, Germany, p. 292.

Duncan N (2012) Geothermal Tunnel Linings Principles of Geothermal Tunnel Linings. Presentation. Arup-Rehau, Geothermal Tunnel Lining Conference, 19 October 2012, London.

Franzius JN and Pralle N (2011) Turning segmental tunnels into sources of renewable energy. Proceedings of ICE - Civil engineering 164(1): 35-40.

Laloui L and Di Donna A (2011) Understanding the behaviour of energy geo-structures. Proceedings of the ICE-Civil Engineering 164(4): 184-191.

Lee C, Park S, Won J et al. (2012) Evaluation of thermal performance of energy textile installed in tunnel. Renewable Energy 42: 11-22.

Markiewicz R and Adam D (2003) Utilisation of geothermal energy using earthcoupled structure - theoretical and experimental investigations, case histories. In: Geotechnical Problems with Man-Made and Man Influenced Grounds. XIII European Conference on Soil Mechanics and Geotechnical Engineering. Czech Geotechnical Society (CZE), Prague, Czech Republic, August 25-28, 2003, vol. 2, pp. 25-28.

Nicholson DP, Chen Q, Pillai A and Chendorain M (2013) Developments in thermal pile and thermal tunnel linings for city scale GSHP systems. Thirty-Eighth Workshop on 
Geothermal Reservoir Engineering, February 11-13, 2013. Stanford University, Stanford, California.

Schneider M and Moormann C (2010) GeoTU6 - a geothermal research project for tunnels. Tunnel 2: 14-21.

Spitz K and Moreno J (1996) A Practical Guide to Groundwater and Solute Transport Modelling. John Wiley \& Sons, Inc., NY, USA, p. 461.
Wilhelm J and Rybach L (2003) The geothermal potential of Swiss alpine tunnels - forecasts and valorization. European Geothermal Conference, Szeged, Hungary.

Zhang G, Xia C, Sun M, Zou Y and Xiao S (2013) A new model and analytical solution for the heat conduction of tunnel lining ground heat exchangers. Cold Region Science Technology 88: 59-66.

\section{WHAT DO YOU THINK?}

To discuss this paper, please submit up to 500 words to the editor at journals@ice.org.uk. Your contribution will be forwarded to the author(s) for a reply and, if considered appropriate by the editorial panel, will be published as a discussion in a future issue of the journal. 